\title{
Rcan1 Deficiency Impairs Neuronal Migration and Causes Periventricular Heterotopia
}

\author{
Yang Li, ${ }^{1,2}$ Jie Wang, ${ }^{1,2}$ Yang Zhou, ${ }^{1}$ Dan Li, ${ }^{1,2}$ and Zhi-Qi Xiong ${ }^{1}$ \\ ${ }^{1}$ Institute of Neuroscience, State Key Laboratory of Neuroscience, CAS Center for Excellence in Brain Science, Shanghai Institutes for Biological Sciences, \\ Chinese Academy of Sciences. Shanghai 200031, People's Republic of China, and 2University of Chinese Academy of Sciences, Shanghai 200031, People's \\ Republic of China
}

Periventricular heterotopia (PH) is a cortical malformation characterized by aggregation of neurons lining the lateral ventricles due to abnormal neuronal migration. The molecular mechanism underlying the pathogenesis of PH is unclear. Here we show that Regulators of calcineurin 1 (Rcan1), a Down syndrome-related gene, plays an important role in radial migration of rat cortical neurons. Downregulation of Rcan1 by expressing shRNA impaired neural progenitor proliferation and led to defects in radial migration and PH. Two isoforms of Rcan1 (Rcan1-1 and Rcan1-4) are expressed in the rat brain. Migration defects due to downregulation of Rcan1 could be prevented by shRNA-resistant expression of Rcan1-1 but not Rcan1-4. Furthermore, we found that Rcan1 knockdown significantly decreased the expression level of Flna, an F-actin cross-linking protein essential for cytoskeleton rearrangement and cell migration, mutation of which causes the most common form of bilateral PH in humans. Finally, overexpression of FLNA in Rcan1 knockdown neurons prevented migration abnormalities. Together, these findings demonstrate that Rcan1 acts upstream from Flna in regulating radial migration and suggest that impairment of Rcan1-Flna pathway may underlie $\mathrm{PH}$ pathogenesis.

Key words: FilaminA; migration; periventricular heterotopia; Rcan1

\section{Introduction}

The development of proper brain organization depends on precise spatial and temporal regulation of the migration of postmitotic neurons. Migration defects due to genetic or environmental factors result in many forms of developmental brain malformation (Olson and Walsh, 2002). Periventricular heterotopia (PH), a disorder associated with intractable epilepsy and intellectual disability, exhibits brain pathology characterized by the formation of ectopic neuronal nodules along lateral ventricles ( $\mathrm{Lu}$ and Sheen, 2005; Sarkisian et al., 2008). The most common familial form of PH is caused by mutations in FilaminA (FLNA) (Fox et al., 1998), which encodes an F-actin cross-linking protein essential for cytoskeleton rearrangement and cell migration. Previous studies showed that both insufficiency and excess of FLNA inhibit migration (Sarkisian et al., 2006; Carabalona et al., 2012), indicating the importance of precise regulation of FLNA expression during neuronal migration.

Regulators of calcineurin 1 (RCAN1), a gene first cloned from the Down syndrome critical region located on human chromo-

\footnotetext{
Received March 13, 2014; revised Nov. 1, 2014; accepted Nov. 6, 2014.

Author contributions: Y.L., Y.Z., and Z.-Q.X. designed research; Y.L., J.W., Y.Z., and D.L. performed research; Y.L. and Y.Z. contributed unpublished reagents/analytic tools; Y.L. analyzed data; Y.L. and Z.-Q.X. wrote the paper.

This work was supported by 973 Program Grant 2011CBA00400 and National Natural Science Foundation of China Grants 91332203, 31123002, and 31321091. We thank Drs. Volney Sheen and Gewei Lian (Harvard Medical School) for the pcDNA-FLNA-EGFP plasmid; and Dr. Mu-Ming Poo for critical reading of the manuscript.

The authors declare no competing financial interests.

Correspondence should be addressed to Dr. Zhi-Qi Xiong, Institute of Neuroscience, Chinese Academy of Sciences, 320 Yueyang Road, Shanghai 200031, People's Republic of China. E-mail: xiongzhiqi@ion.ac.cn.

DOI:10.1523/JNEUROSCI.1003-14.2015

Copyright $\odot 2015$ the authors $\quad 0270-6474 / 15 / 350610-11 \$ 15.00 / 0$
}

some 21 , was originally thought to play an important role in the pathogenesis of Down syndrome (Fuentes et al., 1995). The Rcan 1 gene consists of seven exons and encodes several isoforms through different promoter usage (Harris et al., 2005; Davies et al., 2007). Previous studies show that Rcan1 physically interacts with the calcium-regulated protein phosphatase calcineurin; however, its action on calcineurin phosphatase activity remains controversial (Fuentes et al., 2000; Görlach et al., 2000; Rothermel et al., 2000; Vega et al., 2002, 2003; Hilioti et al., 2004; Martin et al., 2012).

The expression of Rcan 1 is widespread in both developing and adult brain (Fuentes et al., 1995; Casas et al., 2001), and aberrant expression of Rcan 1 impairs many aspects of brain functions (Hoeffer et al., 2007; Martin et al., 2012). For example, the volume of hippocampus and the density of dendritic spines on hippocampal pyramidal neurons are reduced in Rcan1overexpressing mice. Deficits in hippocampus-dependent learning and memory were also observed in these transgenic mice (Martin et al., 2012). Furthermore, Rcan 1 knock-out mice exhibited deficits in learning and memory and late-phase long-term potentiation (Hoeffer et al., 2007). In addition, Rcan1 was found to influence both exocytotic rate and vesicle fusion kinetics (Keating et al., 2008). Although Rcan 1 is expressed in the developing cortex (Casas et al., 2001; Porta et al., 2007), its function during cortical development remains largely unclear. No obvious abnormality was observed in the cortex of Rcan1-null mice (Vega et al., 2003), but this may be attributed to compensatory expression of other members of this gene family (Porta et al., 2007). Here, we studied the function of Rcan 1 in developing rat brain by using in utero electroporation (IUE) (Tabata and Nakajima, 

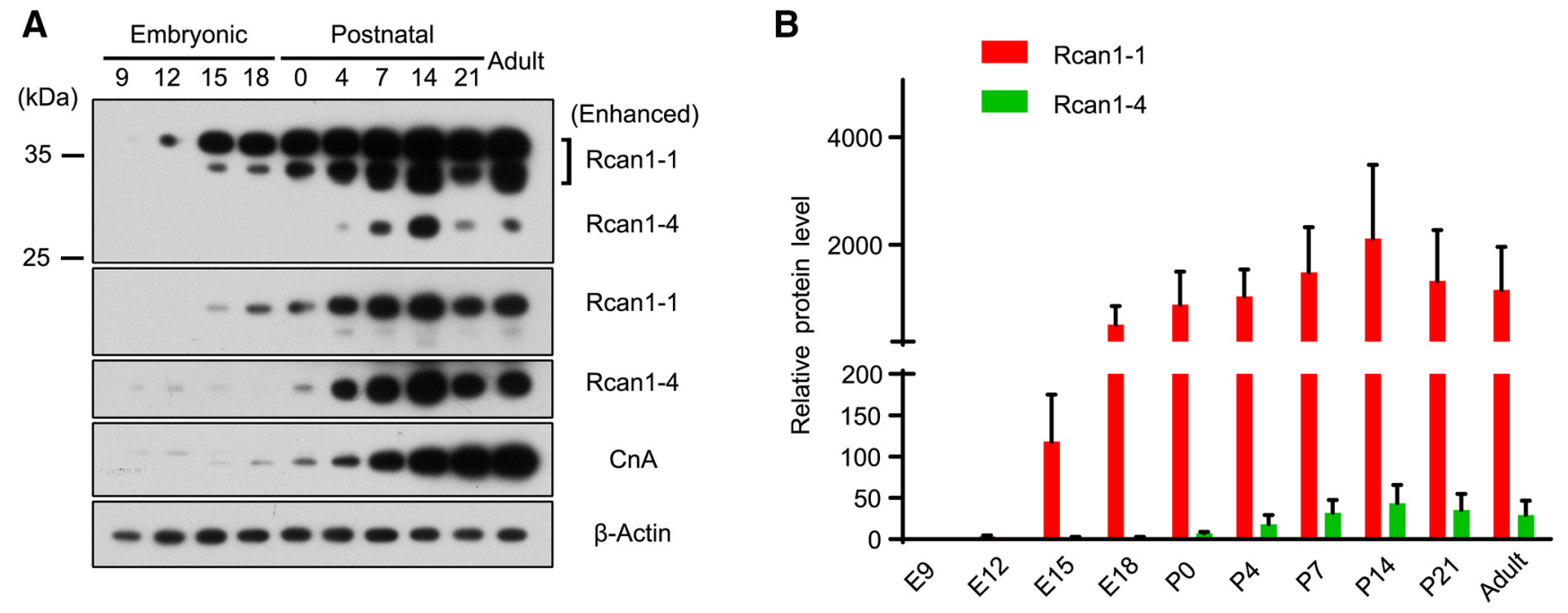

Figure 1. Expression of Rcan 1 isoforms in the developing rat cortex. $\boldsymbol{A}$, Western blot of protein extracts from rat cortices at the indicated time points. Top, Left, The position of protein markers $(\mathrm{kDa})$. The positions of the Rcan1-1 and Rcan1-4 isoforms are indicated. Top, An overexposed image (Enhanced), in which the Rcan1-1 bands with different electrophoretic mobility can be observed. Relative abundant expression of Rcan1-1 can also be observed. Two central panels, Paralleled expression of Rcan1 is oforms. The expression of catalytic A subunit of calcineurin is shown as indicated (CnA). Bottom panel, Immunobloting for $\beta$-actin, used as a loading control. $\boldsymbol{B}$, Quantification of protein levels from Western blots showing that the expression of Rcan1-1 and Rcan1-4 steadily increased until P14 and reduced to a lower level in adult. Data are mean \pm SEM; $n=4$ for Rcan 1-1; $n=3$ for Rcan1-4.

2001; Saito, 2006). We found that Rcan1 downregulation impaired radial migration of cortical neurons and led to the formation of PHs. We further demonstrated that, of the two isoforms (Rcan1-1 and Rcan1-4) identified in the cortex, Rcan1-1 plays the dominant role in regulating neuronal migration. In addition, we presented evidence showing that Rcanl knockdown decreased the expression of Flna at the mRNA level in a calcineurinindependent manner. Finally, exogenous expression of FLNA in Rcan1-knockdown neurons was sufficient to prevent their migration defects. Our findings indicate that the Rcan1-Flna pathway regulates radial migration of cortical neurons and abnormality in this regulation may underlie $\mathrm{PH}$ pathogenesis.

\section{Materials and Methods}

Animals. Pregnant female Sprague Dawley rats were provided by SLAC Laboratory Animal. All experimental procedures were done under the permission of the Bioethics Committee of the Institute of Neuroscience at the Shanghai Institute for Biological Sciences, Chinese Academy of Sciences.

Rat Rcan1-1 and Rcan1-4 cloning and constructs preparation. The cDNAs of rat Rcan1-1 and Rcan1-4 (Ensemble accession numbers ENSRNOT00000002714 and ENSRNOT00000002715) were cloned from a cDNA library of rat cerebral cortex by RT-PCR. To obtain fulllength rat Rcan $1-1$ and Rcan 1-4, 5' end primers (5'-CCA TCG ATA TGG AGG ACG GCG CGG TG-3' for Rcan1-1, 5' -CCA TCG ATA TGC ATT TTA GGG ACT TTA ACT ACA ATT TT-3' for Rcan1-4) were designed. Because Rcan1-1 and Rcan1-4 have the same C-terminals, a common 3' primer (5' -CCC CCG GGT CAG CTG AGG TGG ATG GGT GTG T-3') was used. PCR products were cloned into pCAGGS-IRESGFP vector (provided by Dr. Xiao-bing Yuan) at ClaI/XmaI sites and sequenced. Oligos targeted to different sequences of rat Rcan 1 mRNA, calcineurin $A$, and a scramble oligo were designed, synthesized, and cloned into pSuper-basic (Oligoengine). The 19-nucleotide target sequences are as follows: Rcan $1 \# 1$ shRNA, 5'-AGG AGA TGA AAC TGT ACT T-3'; Rcan 1 \#3 shRNA, 5' -CGT TCA TGC ATG TGT ATT A-3'; calcineurin A, 5' -TGA GAA GAC TCA GGA ACA T-3' and NC-shRNA, 5' -TTC TCC GAA CGT GTC ACG T-3' . The \#1 shRNA-resistant form of Rcan1 (Rcan1-1 $\star$ and Rcan $1-4 \star$ ) were generated by mutating five nucleotides of \#1 shRNA targeting sequence in Rcan1-1 and Rcan1-4 cDNA (from AGG AGA TGA AAC TGT ACT T to AAG AAA TGA AGC TCT ATT T) without changing their corresponding amino acids and cloned into pCAGGS-IRES-GFP vector. The pcDNA-FLNA-EGFP construct was a gift from Dr. Volney Sheen (Department of Neurology, Beth Israel Deaconess Medical Center and Harvard Medical School, Boston).

Western blotting. For mapping the expression of Rcan 1 in developing cortex, cortices were dissected and homogenized as previously described (Li et al., 2009). For knockdown and rescue experiment, electroporated cortical neurons were cultured for 4-6 d, and lysed in $1 \times$ protein loading buffer (50 mm Tris- $\mathrm{HCl}, \mathrm{pH} 6.8,2 \%$ SDS, $10 \%$ glycerol, $1 \%$ 2 -ME, and $0.1 \%$ bromophenol blue). When measuring Flna expression, electroporated cortical neurons were cultured for $6 \mathrm{~d}$ and lysed in RIPA buffer (50 mu Tris, pH 8.0, $150 \mathrm{~mm} \mathrm{NaCl,1 \%} \mathrm{NP-40,} \mathrm{0.1 \%} \mathrm{SDS,} \mathrm{0.5 \%}$ sodium deoxycholate, 1 mm PMSF, 5 mM EDTA, 1 mm EGTA, 10 mм Na fluoride, and $1 \mathrm{~mm} \mathrm{Na}$ orthovanadate). All protein samples were separated by $10 \%$ SDS-polyacrylamide gel electrophoresis (Bio-Rad) and blotted onto PVDF membrane (Millipore). Membranes were blocked with 5\% no-fat milk in $0.05 \%$ Tween 20 at room temperature for $1 \mathrm{~h}$ and probed with rabbit anti-Rcan1 (Sigma), rabbit anti-calcineurin (Santa Cruz Biotechnology), HRP-coupled mouse anti- $\beta$-actin (Santa Cruz Biotechnology), and rabbit anti-Flna (Epitomics) antibodies. The secondary antibody used was goat anti-rabbit IgG coupled to HRP (Santa Cruz Biotechnology). Bands were visualized by enhanced chemiluminescence (TIANGEN). Band intensities were measured with ImageJ Software.

Cell culture and electroporation. Primary cortical neurons were prepared from brains of embryonic day 18 (E18) or postnatal day 1 (P1) Sprague Dawley rat as described previously (Zhou et al., 2006). Before plating, neurons suspended in transfection medium $(200 \mu \mathrm{l})$ were mixed with $1 \mu \mathrm{g}$ pCAG-EGFP and $3 \mu \mathrm{g}$ shRNA for immunocytochemistry, $10-20 \mu \mathrm{g}$ shRNAs, and $5 \mu \mathrm{g}$ Rcan $1-1 \star$ or Rcan $1-4 \star$ for immunobloting and calcineurin phosphotase activity assay. Then, neurons were transferred into a $2.0 \mathrm{~mm}$ electroporation cuvette (Fisher), and transfected by electroporation using the Amaxa Nucleofector apparatus (Amaxa).

IUE. IUE was performed as described previously (Li et al., 2009). In brief, E16 embryos of Sprague Dawley rats were exposed, and 1-2 $\mu \mathrm{l}$ plasmid solution mixed with Fast Green was injected into the lateral ventricle. Then, embryos were clamped between $10 \mathrm{~mm}$ diameter tweezers-type disc electrodes (CUY650-10; SONIDEL), and five $50 \mathrm{~ms}$, $60 \mathrm{~V}$ electric pulses at an interval of $950 \mathrm{~ms}$ were given by an electroporator (ECM830; BTX). Plasmids were prepared at a concentration of 0.3 $\mu \mathrm{g} / \mu \mathrm{l}$ for pCAG-EGFP, $0.9 \mu \mathrm{g} / \mu \mathrm{l}$ for shRNAs, and $2.5 \mu \mathrm{g}$ for pCAGGSRcan1-1 -IRES-GFP or for pCAGGS-Rcan 1-4 4 -IRES-GFP, $5.3 \mu \mathrm{g}$ for pcDNA-FLNA-EGFP. For assay proliferation of the progenitor cells, 
$\mathrm{BrdU}$ (Sigma) was injected at $100 \mu \mathrm{g} / \mathrm{g}$ intraperitoneally twice every $30 \mathrm{~min}, 24 \mathrm{~h}$, or $48 \mathrm{~h}$ after IUE.

Immunohistochemistry and immunocytochemistry. For immunofluorescence histochemistry, electroporated brains were removed and fixed in 4\% PFA after transcardial perfusion at the indicated time point. The tissues were frozen embedded in OCT compound (Sakura). Coronal brain sections of 40 $\mu \mathrm{m}$ were cut on a freezing microtome, washed with PBS, and blocked in 5\% BSA plus $0.3 \%$ Triton X-100. Slices were then incubated with antibodies overnight. The primary antibodies used were as follows: rabbit anti-GFP (Invitrogen), mouse anti-BrdU (Millipore), rabbit anti-Ki-67 (Abcam), rabbit anti-Sox2 (Abcam), rabbit-antiTuj1 (Sigma), mouse-anti-GFAP (Millipore), mouse-anti-NeuN (Millipore), and goat-antidoublecortin (Santa Cruz Biotechnology). Fluorescently conjugated Alexa-488 or Alexa-546 (Invitrogen) was used as secondary antibodies. Images were acquired on a NIKON TE2000 or NIKON FN1 microscope with $10 \times$ objective. The numbers of transfected cells in the slices were counted by using the software Image-Pro Plus 6.0. For immunofluorescence cytochemistry, cultured cortical neurons were fixed and immunostained $4 \mathrm{~d}$ after electroporation. The primary antibody used was rabbit anti-Rcan1 (Sigma). Fluorescently conjugated goat anti-rabbit Alexa-546 (Invitrogen) was used as secondary antibody. Images were acquired on a NIKON FN1 microscope with $10 \times$ objective. For both brain slices and cultured neurons, Hoechst 33342 (Beyotime) was used to identify cellular nuclei.

Calcineurin phosphotase activity assay. A calcineurin assay kit (AK-804, Enzo Life Sciences) was used to measure calcineurin activity according to the manufacturer's procedure. Briefly, electroporated cortical neurons were plated on poly-D-lysine-coated 6-well plates at a density of $\sim 2.5 \times 10^{6}$ cells per well. At $6 \mathrm{~d}$ after electroporation, cells were washed 3 times with ice-cold TBS buffer ( $20 \mathrm{~mm}$ Tris, $\mathrm{pH}$ 7.2, $150 \mathrm{~mm} \mathrm{NaCl}$ ), suspended in $100 \mu$ l lysis buffer (provided in kit), and then lysed by three freeze-thaw cycles (liquid $\mathrm{N}_{2} / 30^{\circ} \mathrm{C}$ ). Cell debris was spun down $\left(10,000 \times g, 10 \mathrm{~min}, 4^{\circ} \mathrm{C}\right)$, and supernatant was collected. Protein concentrations were measured by using a BCA protein assay kit (TIANGEN). The final concentration of each sample was adjusted to 0.4 $\mu \mathrm{g} / \mu \mathrm{l}$. The OA $-(\mathrm{OA}+\mathrm{EGTA})$ method was used to detect the calcineurin phosphotase activity.

Real-time PCR. Total cellular RNA was extracted from cultured cortical neurons at $6 \mathrm{~d}$ after electroporation by using an RNeasy Mini Kit (QIAGEN). Reverse transcription was performed by using iScript cDNA Synthesis Kit (Bio-Rad). We performed real-time PCR of Rcan1 expression by using a LightCycler RNA Master SYBR Green I kit (Roche) in a LightCycler 480 Real-Time PCR System (Roche) according to the manufacturer's instructions. A pair of primers was designed to detect Flna mRNA, and the sequences are listed as follows: 5' -GAG AGG TGC TGG TAT ATG-3' and 5' -CGG TTC TTG TCG TTA TTG- $3^{\prime}$. For detecting Il-2 mRNA, the following primers were

B

\section{C}
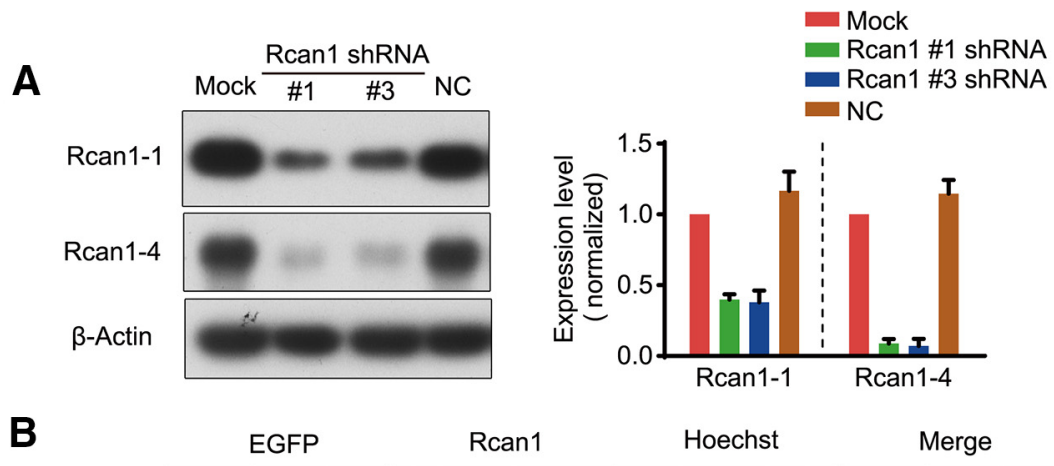

Hoechst
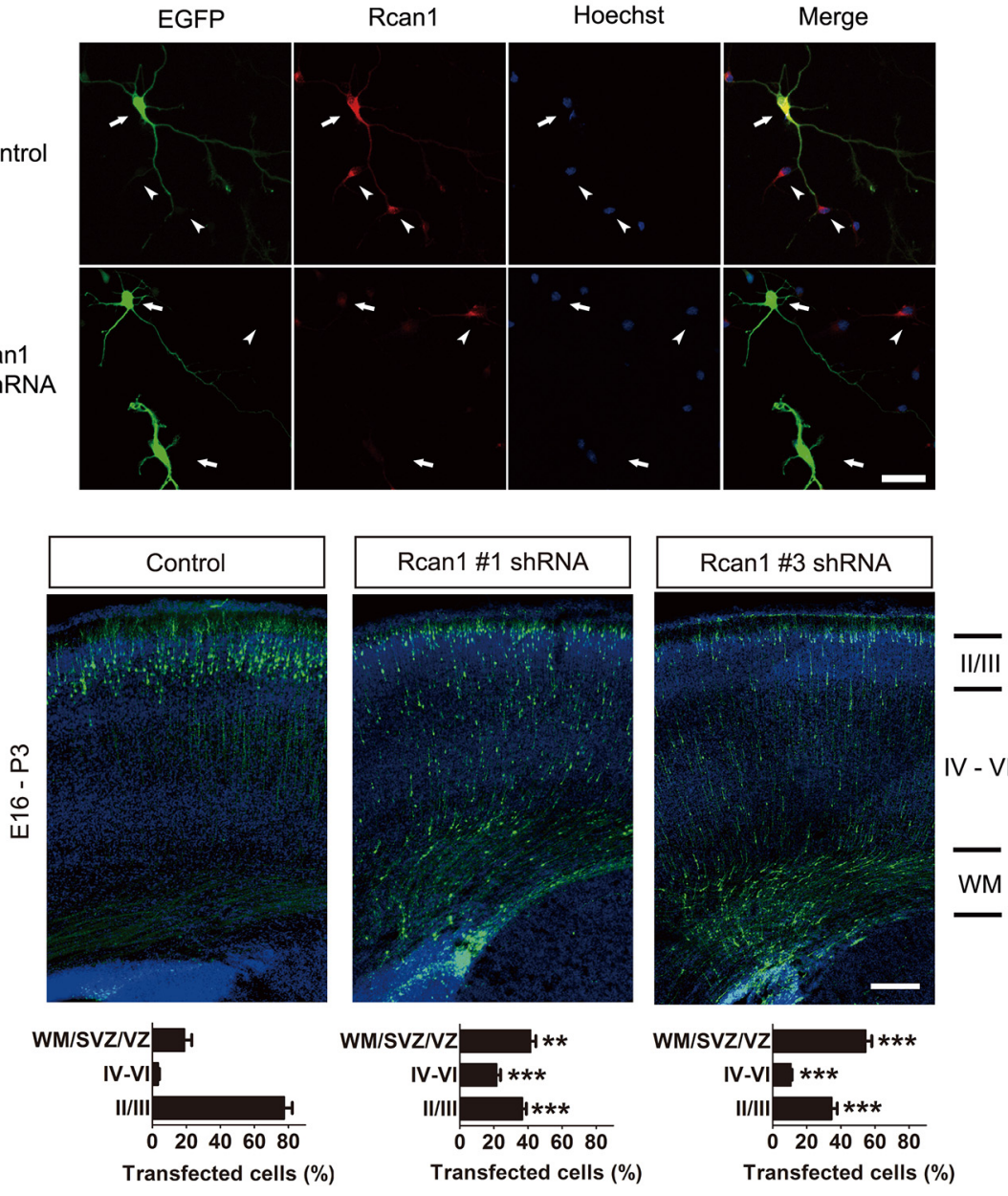

Figure 2. Knockdown of Rcan1 in vivo impairs neuronal migration. $\boldsymbol{A}$, Western blot analysis of Rcan1 shRNAs knockdown efficiency. Protein extracts from cortical neurons transfected with Rcan1 \#1, \#3 shRNA, or pSuper-scramble (NC) were immunoblotted with Rcan1 antibody. $\beta$-Actin was used as a loading control. Mock indicates lysates of untransfected cells. Right, Quantification of Rcan1 protein levels from Western blots showing that both \#1 and \#3 shRNA suppressed Rcan1 expression effectively. Data are mean $\pm \mathrm{SEM} ; n=3$. $\boldsymbol{B}$, Immunocytochemistry showing that \#1 shRNA reduced Rcan1 expression in cultured cortical neurons. Expression of Rcan1 was significantly suppressed in \#1 shRNA-transfected neurons (bottom, arrows) compared with neighboring untransfected neurons (bottom, arrowheads). DIV 0 cortical neurons were transfected with indicated palsmids plus pCAG-EGFP. At DIV 4, neurons were fixed and immunostained with antibody against Rcan 1 (red). Nuclei were visualized by Hoechst staining (blue). Scale bar, $20 \mu \mathrm{m}$. C, Coronal sections of cerebral cortices at P3 electroporated with the indicated plasmids together with pCAG-EGFP at E16. Green represents cells derived from transfected cortical progenitor cells. Sections were counterstained with Hoechst (blue). Cortical layers are indicated on the right. Scale bar, $200 \mu \mathrm{m}$. Bottom, Statistics of cell migration. The percentage of EGFP-labeled cells in the II/III, IV-VI, and WM/SVZ/VZ was calculated and plotted as mean \pm SEM; $n=4-19$ in each group. ${ }^{* *} p<0.01$ ( $t$ test). ${ }^{* * *} p<0.001$ ( $t$ test). II/III, Layer II/III of the cortical plate; IV-VI, layer IV-VI of the cortical plate; WM, white matter; SVZ, subventricular zone; VZ, ventricular zone.

used: 5'-AAG CAG GCC ACA GAA TTG A-3' and 5'-ATT TCC AGC GTC TTC CAA GT-3'. The mRNA of GAPDH was used as a loading control, and the primers used for GAPDH are as follows: $5^{\prime}$-CCC CAA TGT ATC CGT TGT G-3' and 5'-CTC AGT GTA GCC CAG GAT GC-3'. 
A

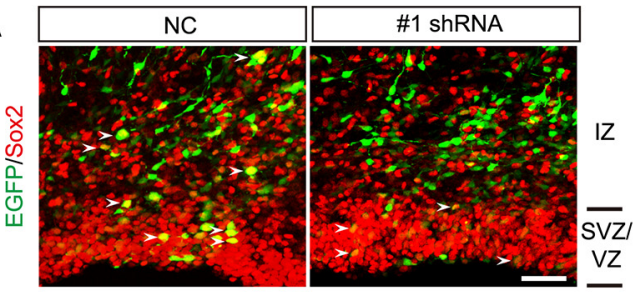

C

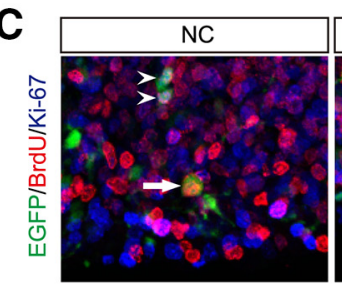

E

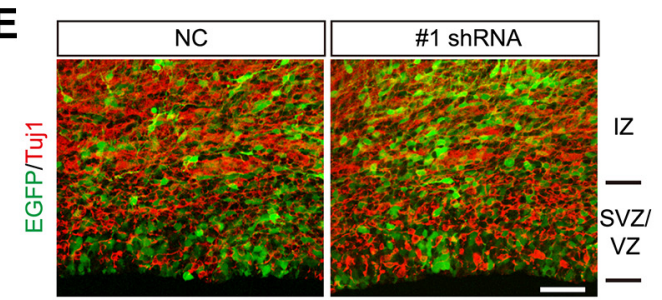

G

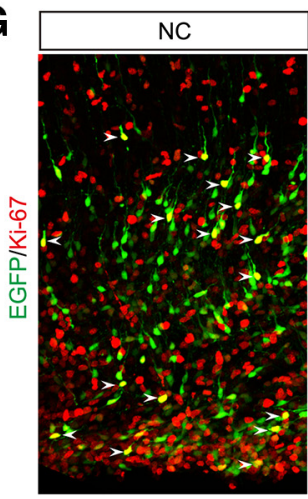

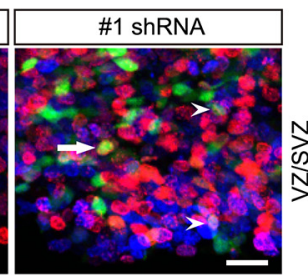

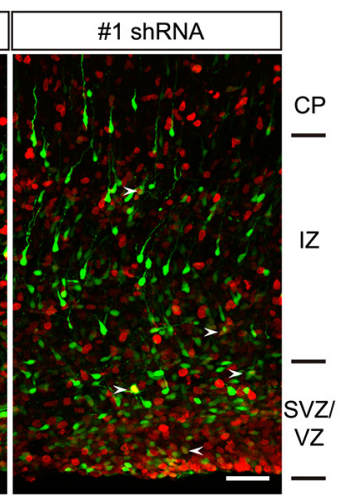

B
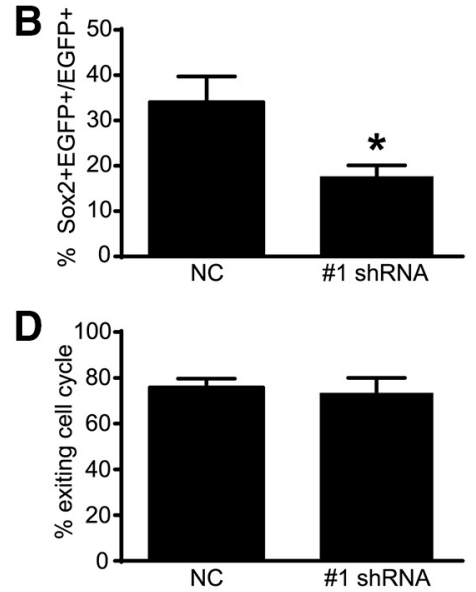

$\mathbf{F}$

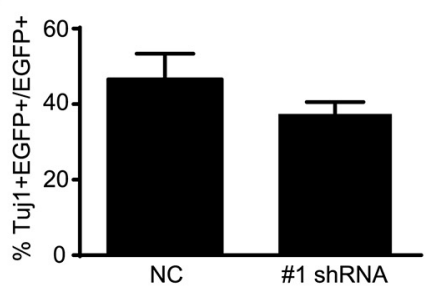

H

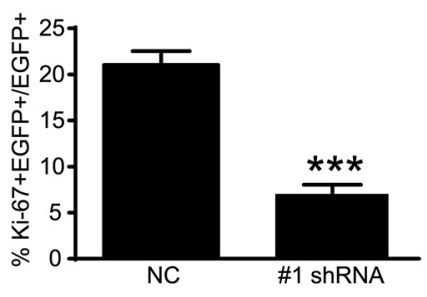

Figure 3. Knockdown of Rcan 1 in vivo impairs neural progenitor proliferation. $A$, Representative confocal images showing the immunostaining of EGFP (green) and Sox2 (red) in E19 cortices electroporated at E16 with EGFP plus scramble (NC) or Rcan1 \#1 shRNA (\#1 shRNA). Arrowheads indicate EGFP and Sox2 double-positive cells. Scale bar, $50 \mu \mathrm{m}$. B, Bar graph represents the percentage of Sox 2 and EGFP double-positive cells to total EGFP-positive cells. ${ }^{*} p<0.05$ ( $t$ test). NC: $n=5$; Rcan $1 \# 1$ shRNA: $n=$ 7. Data are mean \pm SEM. $\boldsymbol{C}, \boldsymbol{D}$, Representative confocal images $(\boldsymbol{C})$ and statistics results $(\boldsymbol{D})$ showing that Rcan1 knockdown decreased cell cycle exit in utero. Scrambled or Rcan1 \#1 shRNA constructs in combination with EGFP were electroporated into E16 embryonic brains, and BrdU was injected at E18. Rats were killed at E19. The cell cycle exit index was measured as the percentage of the EGFP-positive cells that exited the cell cycle (EGFP ${ }^{+} \mathrm{BrdU}^{+} \mathrm{Ki}^{-67}{ }^{-}$) divided by total EGFP and BrdU double-positive $\left(\mathrm{EGFP}^{+} \mathrm{BrdU}^{+}\right)$cells. Arrowheads indicate EGFP ${ }^{+} \mathrm{BrdU}^{+} \mathrm{Ki}^{-} 67^{+}$cells. Arrows indicate EGFP ${ }^{+} \mathrm{BrdU}^{+} \mathrm{Ki}-67^{-}$cells. $p=0.77$ ( $t$ test). NC: $n=6$; Rcan $1 \# 1$ shRNA: $n=6$. Data are mean \pm SEM. Scale bar, $20 \mu \mathrm{m}$. , Representative confocal images showing the localization of transfected cells (green) and Tuj1 immunofluorescence (red). Scale bar, $50 \mu \mathrm{m}$. $\boldsymbol{F}$, Quantification of the data obtained as in $\mathbf{G} . p=0.27$ ( $t$ test). NC: $n=4 ;$ Rcan1 \#1 shRNA: $n=4$. Data are mean \pm SEM. G, Representative confocal images showing the immunostaining of EGFP (green) and Ki-67 (red) in E19 cortices electroporated at E16 with EGFP plus scramble (NC) or Rcan 1 \#1 shRNA (\#1 shRNA). Arrowheads indicate EGFP and Ki-67 double-positive cells. Scale bar, $50 \mu \mathrm{m}$. $\boldsymbol{H}$, Bar graph represents the percentage of Ki-67 and EGFP double-positive cells to total EGFP-positive cells. ${ }^{* * *} p<0.0001$ ( $t$ test). NC: $n=6$; Rcan1 \#1 ShRNA: $n=6$. Data are mean \pm SEM.CP, Cortical plate; IZ, intermediate zone; SVZ, subventricular zone; VZ, ventricular zone.

sistent with previous reports (Porta et al., 2007; Martin et al., 2012), two Rcan1 protein isoforms (Rcan1-1 and Rcan1-4) were detected, with Rcan1-1 being more abundant (Fig. 1A). The expression of both isoforms steadily increased and peaked at postnatal day 14 (P14) during development, and slightly reduced to a lower level in adult (Fig. 1A,B).

\section{Rcan1 downregulation impairs radial migration}

To examine whether Rcan 1 contributes to cortical development, we generated short hairpin RNAs (shRNAs) to knock down the expression of Rcan 1 . The efficiency of these shRNAs was first tested in primary cultures of cortical neurons by Western blot analysis. Among these shRNAs tested, \#1 and \#3 shRNA suppressed both Rcan1-1 and Rcan1-4 effectively (Fig. 2A). In addition, immunostaining for Rcan 1 revealed that \#1 shRNA markedly reduced Rcan 1 expression in these cultured neurons (Fig. 2B), further confirming the knockdown efficiency. To investigate the potential function of Rcan1 in radial migration of cortical neurons, plasmids encoding \#1 shRNA and EGFP were transfected into the developing rat cortex at E16 by using IUE (Saito, 2006) and the distribution of EGFP-labeled cells was examined at P3. Whereas the majority of the cells expressing scrambled (Control) shRNA $(77.6 \pm 4.7 \%)$ migrated to the layer II/III, only a small percentage of \#1 shRNAexpressing cells $(36.7 \pm 2.3 \%)$ migrated into layer II/III, with the most labeled cells remaining in deeper layers (Fig. 2C). Knockdown Rcan1 by another shRNA (\#3 shRNA) also caused similar migration defect (Fig. 2C). Together, these results indicate that Rcan1 is essential for radial migration of cortical neurons.

\section{Rcan1 downregulation impairs cortical progenitor proliferation}

Previous reports have demonstrated that, during cortical development, Rcan 1 is highly expressed in the ventricular zone, a region rich in neural progenitors (Casas et al., 2001). To examine whether Rcan 1 regulates progenitor development, brains that were transfected at E16 with \#1 shRNA or scrambled shRNA together with EGFP were immunostained at $72 \mathrm{~h}$ after electropora-

Statistical analysis. Statistical results are presented as mean \pm SEM. The significance of differences was determined by $t$ test compared with control group using Prism 5.0 software.

\section{Results}

Rcan1 expression in developing rat cortex

The temporal regulation of Rcan1 expression during rat brain development was determined by Western blot analysis of protein extracts of rat cortices from embryonic day 9 (E9) to adult. Con- tion for the neural progenitor marker Sox2. In brains transfected with scrambled shRNA, $34.0 \pm 5.7 \%$ of EGFP-expressing cells were Sox2-positive, whereas in brains transfected with Rcan1 \#1 shRNA, the percentage of Sox2-positive cells $(17.7 \pm 2.4 \%)$ was significantly decreased $(p<0.05$ ) (Fig. $3 A, B)$, suggesting that knockdown Rcan1 decreases neural progenitor pool size.

The decreased progenitor pool size may be due to premature neuronal differentiation or impaired progenitor proliferation. To 
examine whether Rcan 1 knockdown could lead to premature differentiation, we measured the ratio of cells that exit the cell cycle (Chenn and Walsh, 2002; Mao et al., 2009). Brains were electroporated with scrambled shRNA or Rcan 1 \#1 shRNA together with EGFP at E16, pulse labeled by BrdU at E18, and analyzed at E19 by immunostaining with BrdU and Ki-67 antibodies. The Ki-67 antigen labels all cells in the cell cycle ( $G_{1}, S, G_{2}$, and $M$ phases), but not those exiting cell cycle. The cell cycle exit index was measured as the percentage of the EGFP-positive cells that exited the cell cycle $\left(\mathrm{EGFP}^{+} \mathrm{BrdU}^{+} \mathrm{Ki}^{-} 7^{-}\right.$) divided by total EGFP and BrdU double-positive $\left(\mathrm{EGFP}^{+} \mathrm{BrdU}^{+}\right)$cells. A slight decrease in cell cycle exit was observed in the Rcan1 knockdown cortices $(73.5 \pm 6.5 \%)$ compared with the control cortices (75.8 \pm $3.9 \%$ ) (Fig. 3C,D), indicating a decline in neural differentiation. Consistently, costaining with the neuronal marker Tuj1 also showed decreased ratio of colabeling with the EGFP-positive cells in the Rcan1 knockdown cortices $(37.5 \pm 3.1 \%)$ compared with control $(46.6 \pm 6.8 \%$ ) (Fig. 3E,F). These findings indicate that premature differentiation is not the cause of the decreased progenitor pool size.

We next examined the effect of Rcan 1 knockdown on progenitor proliferation. In brains transfected with scrambled shRNA, $21.0 \pm 1.5 \%$ of EGFP-expressing cells were Ki-67-positive, whereas in brains transfected with Rcan 1 \#1 shRNA, the percentage of Ki-67-positive cells (7.2 $\pm 0.9 \%)$ was significantly decreased $(p<0.0001)$ (Fig. $3 G, H)$. Together, these results suggest that the decreased progenitor pool size in Rcan 1 knockdown brains is a result of impaired progenitor proliferation.

\section{Rcan1 downregulation causes $\mathrm{PH}$}

$\mathrm{PH}$ is characterized by heterotopic neuronal clusters lining the lateral ventricles ( $\mathrm{Lu}$ and Sheen, 2005). Interestingly, we observed ectopic nodules of EGFP-positive cells lining the ventricular walls in most of \#1 shRNA-transfected cortices (80\%) when examined at P7. These ectopic nodules were found to invade the hippocampus (Fig. $4 A, B^{\prime \prime}$ ), indicating disruption in junctional integrity and neuroepithelial organization of the ventricular wall between the cortex and hippocampus. The cells in the nodule exhibited neurite-like structure (Fig. 4C), suggesting that the nodules are comprised of neurons.

Cell types within the nodules were examined by immunostaining with specific markers. We found most \#1 shRNA-transfected $\left(\mathrm{EGFP}^{+}\right)$cells costained with newborn neuronal marker Doublecortin, and very few costaining was found for the mature neuronal marker NeuN or astrocyte marker
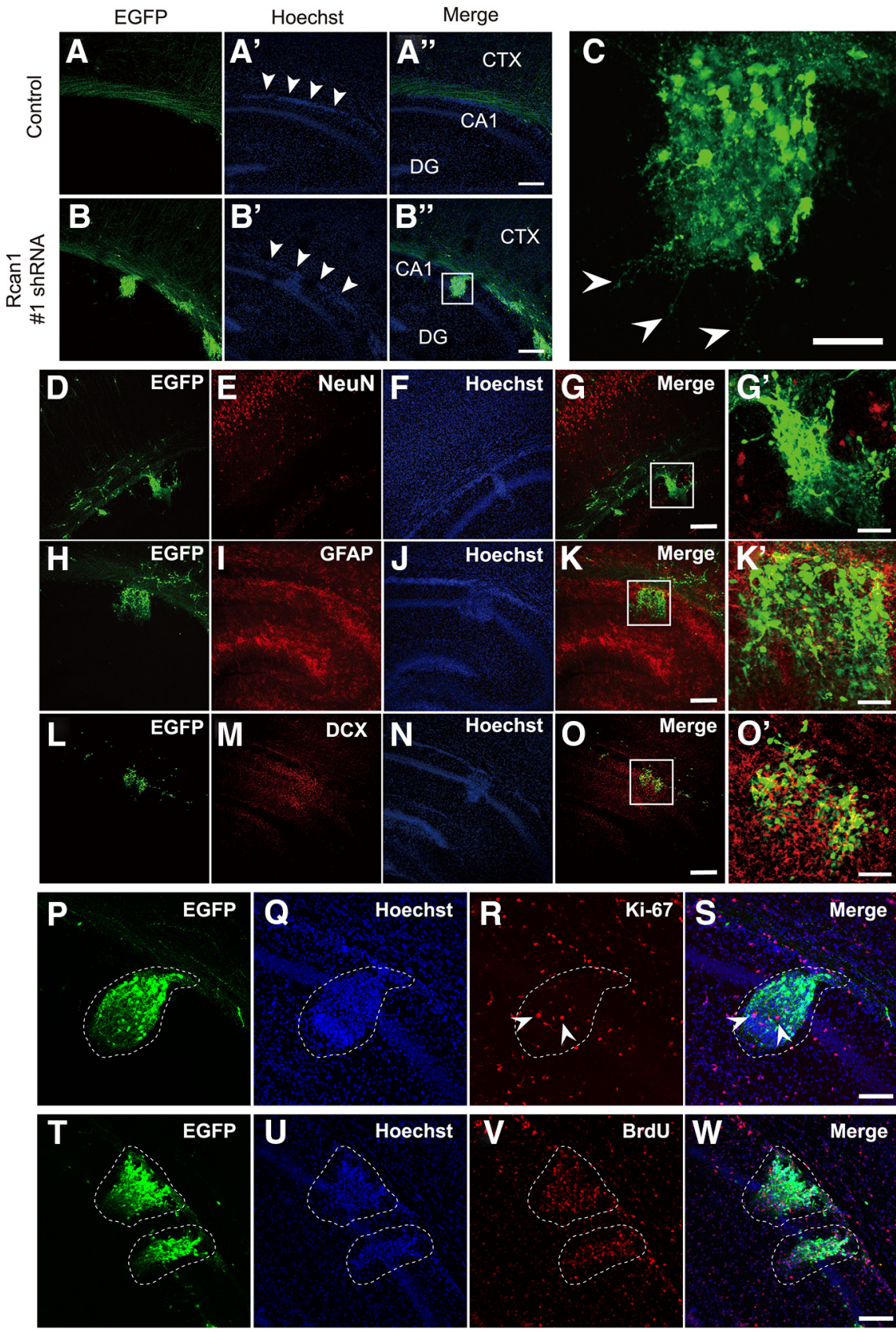

Figure 4. Knockdown of Rcan1 leads to the formation of PH. $A-B^{\prime \prime}$, Representative coronal sections showing the PH in Rcan1 knockdown brains. E16 rat embryos were electroporated with either EGFP plus scramble shRNA $\left(A, A^{\prime \prime}\right)$ or EGFP plus Rcan $1 \# 1$ shRNA $\left(\boldsymbol{B}-\boldsymbol{B}^{\prime \prime}\right)$ and analyzed at P7. EGFP-positive ectopic nodules can be observed in the Rcan1 knockdown brains; these nodules even invaded the hippocampus $\left(\boldsymbol{B}-\boldsymbol{B}^{\prime \prime}\right)$. In control brains, the neuroepithelial organization of the ventricular walls was well kept as shown by the continual Hoechst staining ( $\boldsymbol{A}^{\prime}$, arrowheads), whereas in the Rcan1 \#1 shRNA brains, the continuity ( $\boldsymbol{B}^{\prime}$, arrowheads) was disrupted by the ectopic nodule ( $\boldsymbol{B}^{\prime}, \boldsymbol{B}^{\prime \prime}$, outlined area). $\boldsymbol{C}$, Magnified image of the outlined area in $\boldsymbol{B}^{\prime \prime}$ showing that cells in the nodule exhibited neurite-like structure (arrowheads). $\boldsymbol{D}-\mathbf{O}^{\prime}$, Immunostaining of Rcan1 $\# 1$ shRNA brain sections at $P 7$ revealed that cells in the nodules were immunonegative for the mature neuronal marker $\operatorname{NeuN}(\boldsymbol{D}-\boldsymbol{G})$ and the astrocyte marker GFAP $(\boldsymbol{H}-\boldsymbol{K})$, but immunopositive for the newborn neuronal marker Doublecortin $(\boldsymbol{L}-\mathbf{O})$. Areas outlined in $\mathbf{G}, \boldsymbol{K}$, and $\boldsymbol{O}$ point to the heterotopias are shown at higher magnification in $\mathbf{G}^{\prime}, \boldsymbol{K}^{\prime}$, and $\boldsymbol{O}^{\prime}$, respectively. $\boldsymbol{P}-\boldsymbol{S}$, Immunostaining of Rcan1\#1 shRNA brain sections at P7 showing no aggregation of Ki-67 signal in the heterotopia. Outlined areas indicate the region of heterotopia. $\boldsymbol{R}$, Arrowheads indicate the presence of Ki-67-positive cells in the heterotopia region. $T$ - $W$, Immunostaining of Rcan1 \#1 shRNA brain sections at P7 showing aggregation of BrdU-positive cells in the heterotopia. Outlined areas indicate the regions of heterotopia. $A^{\prime \prime}, B^{\prime \prime}, C T X$, Cortex; CA1, CA1 pyramidal cell layer in hippocampus; DG, dentate gyrus. Scale bars: $\boldsymbol{A}-\boldsymbol{B}^{\prime \prime}, 200 \mu \mathrm{m} ; \boldsymbol{C}, 50 \mu \mathrm{m} ; \mathbf{D}-\mathbf{0}, 200 \mu \mathrm{m} ; \boldsymbol{G}^{\prime}-\mathbf{O}^{\prime}, 50 \mu \mathrm{m} ; \boldsymbol{P}-\boldsymbol{W}, 100 \mu \mathrm{m}$.

GFAP (Fig. 4D-O'). To further examine whether the heterotopic cells are positive for proliferation marker, we immunostained these cells with Ki-67 antibody. Although some Ki-67-positive cells can be observed in those heterotopias (Fig. $4 R, S$ ), there was 
A

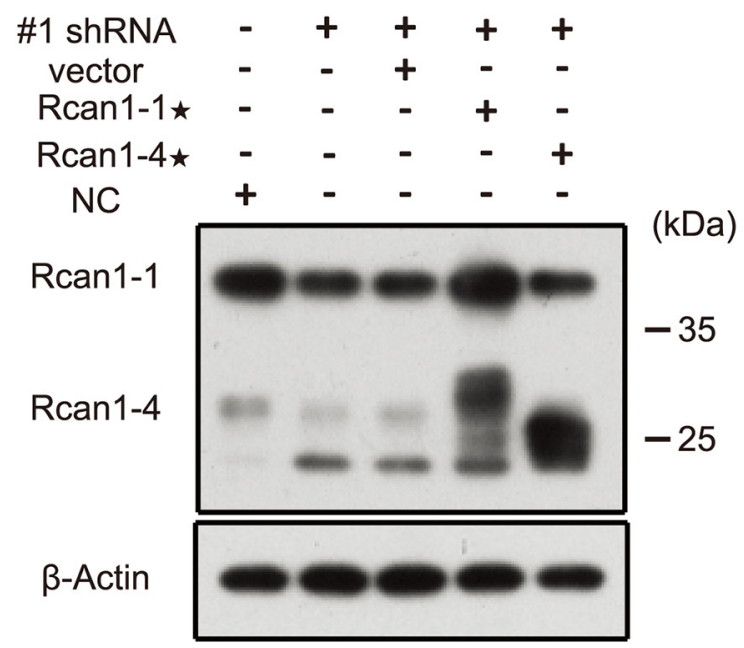

B

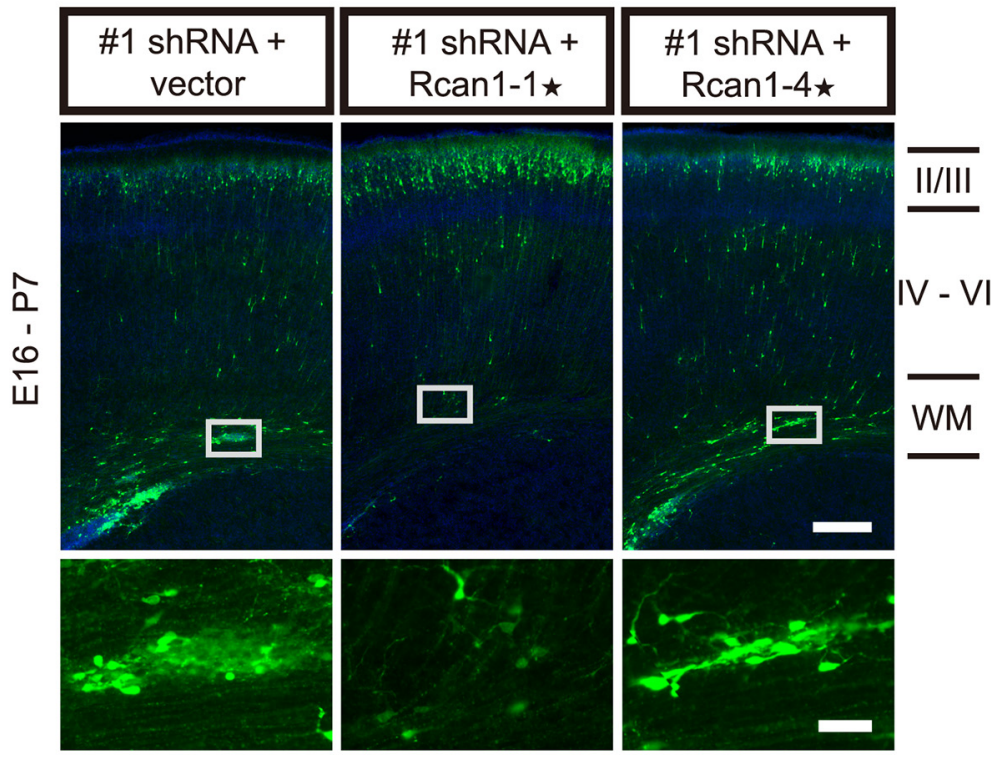

C

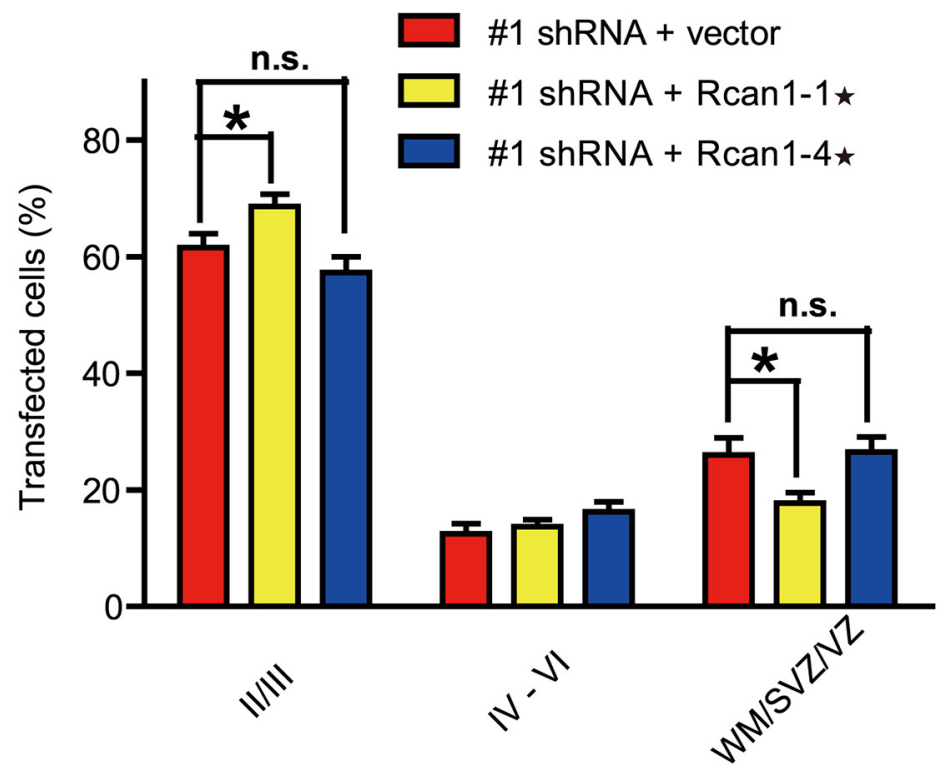

Figure 5. Expression of Rcan1-1, but not Rcan1-4, rescues the radial migration defects of the Rcan 1 knockdown neurons. $\boldsymbol{A}$, Western blot analysis showing that the \#1 shRNA-resistant mutation Rcan1-1 1 and Rcan $1-4 \star$ could restore the expression of Rcan1-1 and Rcan1-4 separately in cultured cortical neurons. The 0 DIV cortical neurons were electroporated with pSuper- no difference in the density of these cells between the heterotopia and the surrounding region (Fig. $4 P-S$ ). Quantitative analysis revealed that none of the EGFP ${ }^{+}$ cells in the heterotopias was colabeled with Ki-67 (8 heterotopias; 502 EGFPpositive cells; 0 colabeling). Together, these results suggest that the heterotopias are mainly composed of newly differentiated neurons.

To identify the origin of the heterotopias, we performed electroporation at E16 and injected BrdU 24 h later. The distribution of BrdU-positive cells in the heterotopia was analyzed at P7. We found that $\sim 75.4 \pm 6.7 \%$ of cells ( 3 heterotopias; 416 cells) in these heterotopias are BrdUpositive (Fig. $4 T-W$ ), indicating that most of the cells in the heterotopias originate from early stage after Rcan 1 knockdown.

\section{Rcan1-1 isoform regulates radial migration}

To test whether the two isoforms of Rcan1 (Rcan1-1 and Rcan1-4) play distinct roles in cortical neuronal migration, we prepared \#1 shRNA-resistant constructs encoding the two isoforms (Fig. 5A) and examined the effect of expressing each of these constructs on the migration of Rcan1-knockdown neurons. Interestingly, we found that transfection with \#1 shRNA-resistant Rcan1-1 partially prevented the migration defect and the abnormal neuronal clustering found at P7, whereas empty construct or Rcan1-4 had no rescue effect (Fig. 5B,C). Thus, Rcan1-1, rather than Rcan1-4, regulates radial neuronal migration.

\section{Rcan1 regulates Flna expression}

The above studies showed that Rcan 1 downregulation impairs radial neuronal

\section{$\leftarrow$}

scramble (NC) or Rcan1 \#1 shRNA alone, or Rcan1 \#1 shRNA combined with PCAGGS-IRES-EGFP empty vector (vector), Rcan 1-1 $1 \star$, or Rcan 1- $4 \star$ as indicated $(+)$. Cells were lysed $4 \mathrm{~d}$ (4 DIV) after electroporation for Western blot. $\beta$-Actin was used as a loading control. $\boldsymbol{B}$, Representative images showing that Rcan1-1, but not Rcan1-4, could partially rescue the migration defect caused by Rcan1 knockdown. The experiment was performed by using Rcan1 \#1 shRNA combined with pCAGGS-IRES-EGFP empty vector (vector), pCAGGS-Rcan1-1 $\star$-IRES-EGFP, or pCAGGS-Rcan1- 4 «-IRES-EGFP. Bottom, Magnified images of outlined areas in the top panel. The abnormal neuronal clustering appeared when \#1 shRNA cotransfected with empty vector (left) or Rcan1-4 (right). Cotransfection with Rcan $1-1 \star$ could rescue the abnormal clustering (middle). Scale bars: Top, $300 \mu \mathrm{m}$; Bottom, $50 \mu \mathrm{m}$. C, Analysis of the distribution of EGFP-positive cells in the cortices of P7. $n=4-19$ in each group. ${ }^{*} p<0.05$ ( $t$ test). n.s., Not significant. II/III, Layer II/III of the cortical plate; IV-VI, layer IV-VI of the cortical plate; WM, white matter; SVZ, subventricular zone; $\mathrm{VZ}$, ventricular zone. 
A

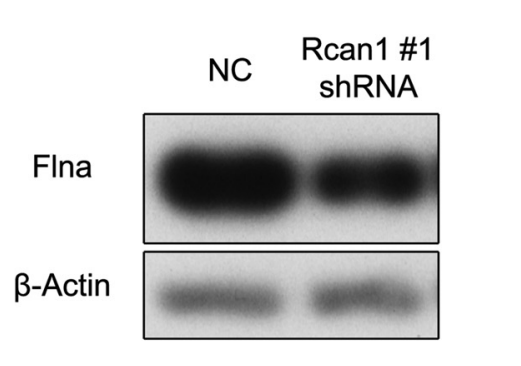

C

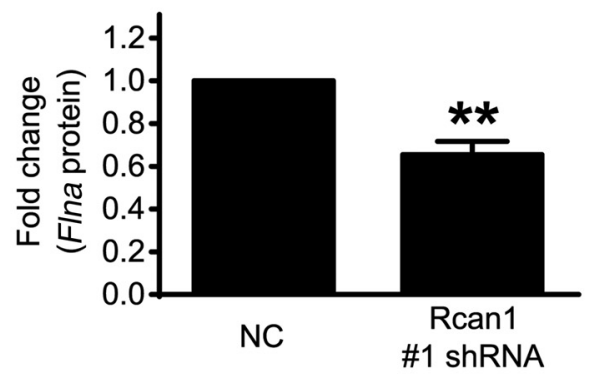

E

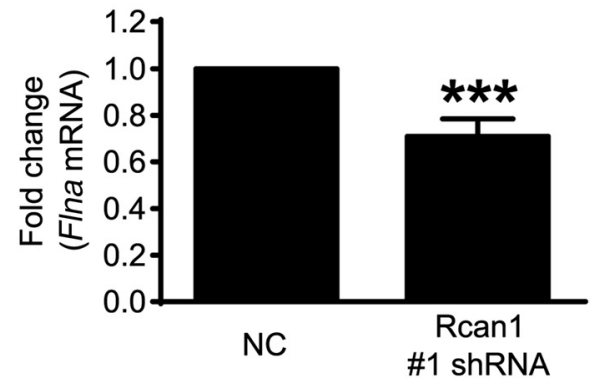

G

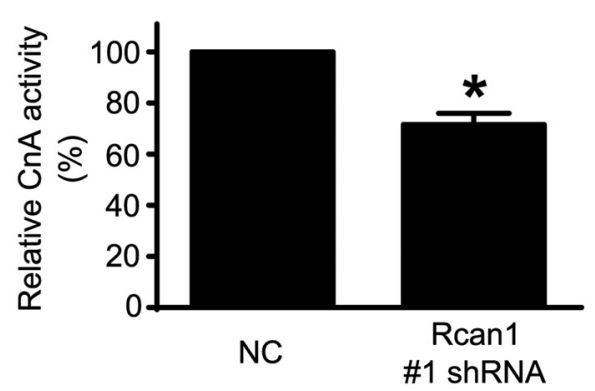

B

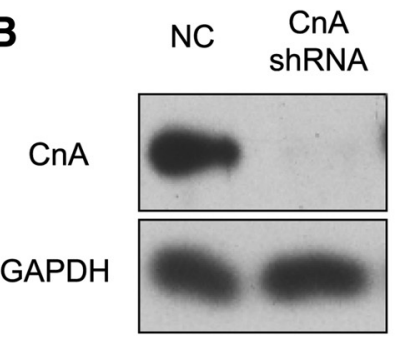

CnA

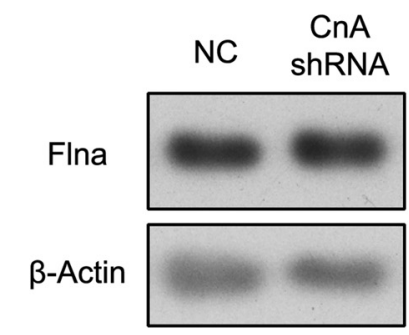

D

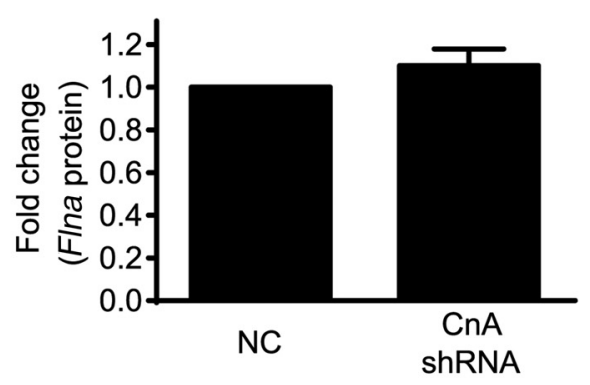

F

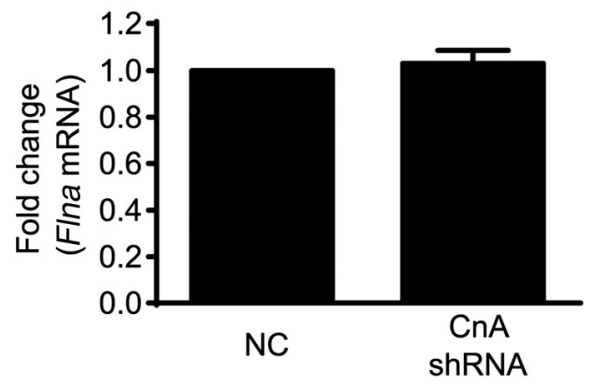

H

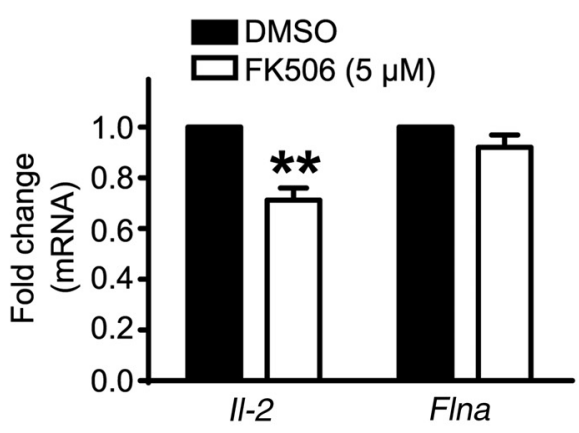

Figure 6. Downregulation of Rcan1 decreases the expression of Flna at the mRNA level. $\boldsymbol{A}, \boldsymbol{B}$, Western blot analysis revealed that the expression of Flna protein was reduced in Rcan1 knockdown neurons $(\boldsymbol{A})$. Although the $\mathrm{CnA}$ shRNA suppressed the expression of $\mathrm{CnA}$ effectively ( $\boldsymbol{B}$, left), no obvious change of Flna protein was observed in these $(n A \mathrm{knockdown}$ neurons $(\boldsymbol{B}$, right). The 0 DIV cortical neurons were electroporated with pSuper-scramble (NC), Rcan1 \#1 shRNA, or CnA shRNA. Cells were lysed $6 \mathrm{~d}$ ( 6 DIV) after electroporation for Western blot. $\beta$-Actin and GAPDH were used as loading controls. C, D, Quantification of the Flna protein levels from Western blots revealed that Rcan 1 knockdown suppressed Flna protein effectively $(\boldsymbol{C})$, whereas $\mathrm{CnA}$ knockdown did not affect Flna protein $(\boldsymbol{D})$. Data are mean $\pm \mathrm{SEM} ; n=7(\boldsymbol{C})$ and $n=6(\boldsymbol{D}) .{ }^{* *} p<0.01$ (paired $t$ test). $\boldsymbol{E}, \boldsymbol{F}$, Real-time PCR showing that knockdown Rcan1 decreased Flna mRNA effectively $(\boldsymbol{E})$, whereas knockdown calcineurin (CnA shRNA) did not affect Flna mRNA $(\boldsymbol{F})$. Data are mean \pm SEM; $n=5(\boldsymbol{E})$ and $n=6(\boldsymbol{F})$. ${ }^{* * *} p<0.001$ (paired $t$ test). G, Calcineurin activity was measured from cultured cortical neurons electroporated with pSuper-scramble (NC) or Rcan1 \#1 shRNA. Cells were lysed $6 \mathrm{~d}$ ( 6 DIV) after electroporation for measurement. Data are mean \pm SEM; $n=6$ in each group. ${ }^{*} p<0.05$ (paired $t$ test). $\boldsymbol{H}$, FK506 treatment did not affect FIna mRNA expression. The 4 DIV cortical neurons were treated with $5 \mu \mathrm{M}$ FK506 for $24 \mathrm{~h}$. Then the mRNA was extracted and analyzed by real-time PCR. Data are mean \pm SEM; $n=4$ in each group. ${ }^{* *} p<0.01$ (paired $t$ test).

migration and causes $\mathrm{PH}$. Previous reports have shown that FilaminA (FLNA) mutation is a major cause of congenital human PH (Fox et al., 1998; Sheen et al., 2001). Interestingly, calcineurin dephosphorylates Ser 2152 of FLNA and renders FLNA susceptible to calpain-dependent degradation (García et al., 2006). Because Rcan 1 has been reported to modulate calcineurin activity, we hypothesized that the migration defect and $\mathrm{PH}$ in Rcan1 knockdown cortex may be attributed to impaired Flna function. To test this hypothesis, we analyzed Flna expression in Rcan1 knockdown cortical neurons. Interestingly, Western blot analysis revealed that Rcan 1 knockdown decreased the Flna protein level (Fig. 6A,C). This decreased protein level could be a result of reduced mRNA expression because real-time PCR showed that Flna mRNA was also significantly decreased in Rcan1 knockdown neurons (Fig. 6E). The extent of reduction in Flna mRNA (70.9 \pm $3.4 \%$ of control) was similar to that of Flna protein $(65.5 \pm 6.2 \%$ of control). Thus, these results suggest that knockdown Rcan1 decreases Flna expression at the mRNA level. 
A
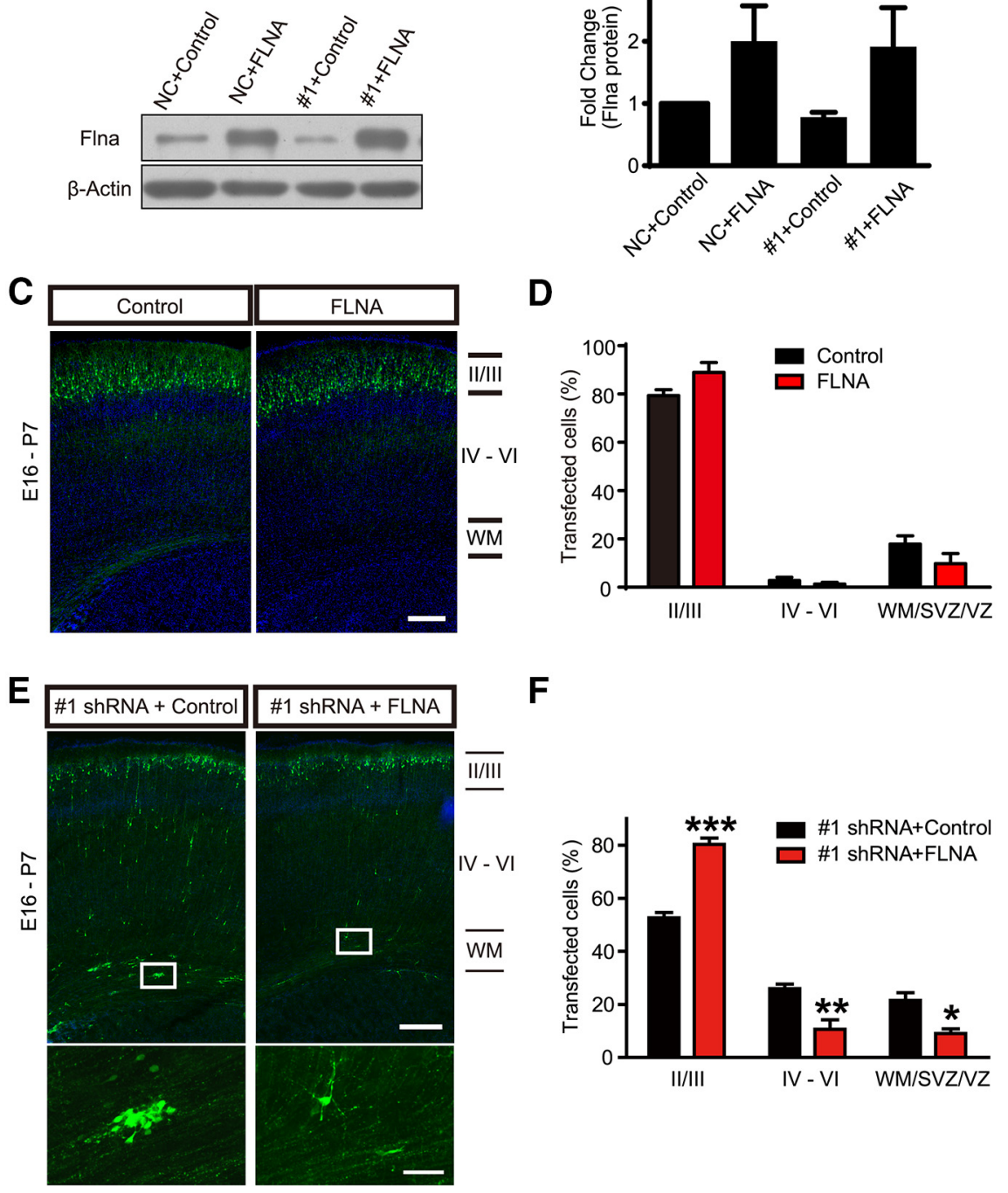

Figure 7. Expression of FLNA rescues the radial migration defect of Rcan1 knockdown neurons. $\boldsymbol{A}$, Western blot analysis showing that expression of the FLNA-EGFP construct increased FLNA protein in cultured cortical neurons. The 0 DIV cortical neurons were electroporated with pSuper-scramble (NC) or Rcan $1 \# 1$ shRNA (\#1) in combination with empty vector (Control) or FLNA-EGFP (FLNA). Cells were lysed $4 \mathrm{~d}$ ( $4 \mathrm{DIV}$ ) after electroporation for Western blot. $\beta$-Actin was used as a loading control. B, Quantification of the data obtained as in $\boldsymbol{A}$. Data are mean \pm SEM; $n=3$. C, $\boldsymbol{D}$, Representative images $(\boldsymbol{C})$ and statistics results $(\boldsymbol{D})$ showing that overexpression of FLNA did not affect neuronal migration at P7. IUE was performed using pCAG-EGFP combined with PCMVEGFP-N1 empty vector (Control) or pcDNA3-FLNA-EGFP (FLNA). Scale bar, $300 \mu \mathrm{m}$. Quantification (mean \pm SEM) of EGFP-positive cell distribution in the cortices of P7. $n=4$ for control; $n=5$ for FLNA; $t$ test. $\boldsymbol{E}, \boldsymbol{F}$, Representative images $(\boldsymbol{E})$ and statistics results (F) showing that FLNA could remarkably rescue the migration defect and neuronal clustering caused by Rcan 1 knockdown. Rescue experiment was performed by using Rcan1 \#1 shRNA combined with pCMV-EGFP-N1 empty vector (Control) or pCDNA3-FLNAEGFP (FLNA). Scale bars: $\boldsymbol{E}$, Top, $300 \mu \mathrm{m} ; \boldsymbol{E}$, Bottom, $50 \mu \mathrm{m}$. Quantification (mean \pm SEM) of EGFP-positive cell distribution in the cortices of P7. $n=9$ for control; $n=4$ for FLNA. ${ }^{*} p<0.05$ ( $t$ test). ${ }^{* *} p<0.01$ ( $t$ test). ${ }^{* * *} p<0.001$ ( $t$ test).

We next analyzed whether calcineurin was involved in the regulation of Rcan1 on Flna expression. First, we found that the calcineurin activity was downregulated in neurons transfected with Rcan1 \#1 shRNA compared with those transfected with scramble shRNA (Fig. 6G). The suppressed activity was not a result of reduced calcineurin expression because the protein level remained the same in these two groups (data not shown). This result is consistent with the previous finding on cardiac extracts from Rcan1-null mice (Vega et al., 2003). Next, we designed a specific shRNA targeted to calcineurin (CnA), and efficient knockdown of calcineurin expression in cultured cortical neurons (Fig. 6B, left) had no significant effect on the level of either Flna protein (Fig. 6B, right) or Flna mRNA (Fig. 6F). To further confirm this result, we used
FK506 to inhibit calcineurin activity (Liu et al., 1991) and then measured the expression level of Flna mRNA. The effectiveness of FK506 was shown by the suppression of interleukin 2 (Il-2) mRNA (Tocci et al., 1989). We found that the level of Flna mRNA in FK506-treated neurons was indistinguishable from that of the control group (Fig. $6 H)$. Together, these results indicate that Rcan1 regulates Flna mRNA through a calcineurin-independent pathway.

\section{FLNA overexpression prevents migration defects of Rcan 1 knockdown neurons}

The finding that Rcan1 regulates Flna expression suggests that the action of Rcan 1 in regulating neuronal migration may be mediated by Flna. To further test this idea, we examined whether overexpression of Flna could prevent the migration defects in neurons with downregulated Rcan1. The expression efficiency of a human FLNA-EGFP construct was tested in cultured cortical neurons. We found that, even cotransfected with Rcan 1 \#1 shRNA, the FLNA protein was significantly overexpressed (Fig. 7A,B). Previous studies have shown that overexpression of Flna in mouse cortices for $4 \mathrm{~d}$ impairs neuronal migration (Sarkisian et al., 2006). However, when Flna was overexpressed in rat brains for a longer time ( $5 \mathrm{~d}$ ), no obvious migration defect was observed, indicating that Flna overexpression may have simply delayed neuronal migration (Carabalona et al., 2012). To further verify this idea, we overexpressed FLNA at E16 and observed its effect on neuronal migration at P7. We found that, even in the FLNA overexpression group, most of the cells could migrate into layer II/III (Fig. 7C,D). A similar result was obtained in mouse when analyzed at P3 (data not shown), ruling out the possible impact due to species difference.

We next examined whether overexpression of Flna in Rcan 1 knockdown neurons could prevent the migration defect. Combined expression of FLNAEGFP with Rcan 1 \#1 shRNA significantly prevented the radial migration defects and the abnormal periventricular neuronal clustering of Rcan1-knockdown neurons (Fig. $7 E, F)$. These data support the notion that Flna acts downstream of Rcan 1 to regulate cortical neuronal migration.

\section{Discussion}

Previous studies (Fuentes et al., 1995; Casas et al., 2001; Porta et al., 2007) and results from this work have shown that Rcan 1 is expressed in the developing cortex. However, in Rcan 1 knockout mice, no obvious abnormality of brain development could be observed (Vega et al., 2003). This may be attributed to compensatory mechanisms in these knock-out mice. By using RNAi technology combined with IUE (Tabata and Nakajima, 2001; Saito, 
2006) that avoids compensatory response due to limited transfection time and efficiency, we show that embryonic knockdown of Rcan1 impairs neuronal radial migration (Fig. 2) and causes the formation of PH (Fig. 4). A recent study suggested a high off-target risk by using shRNA to study neuronal migration (Baek et al., 2014). However, in our study, the migration defect caused by Rcan 1 shRNA can be rescued by expressing the shRNA-resistant form of Rcan1-1 (Fig. 5). This result confirmed the specificity of the shRNA. We also noted that, in our rescue experiment, the migration defect was only partially rescued, suggesting that some off-target effects may exist in our study. Interestingly, earlier reports have shown that Rcan 1 also participates in migration of endothelial cell (Iizuka et al., 2004; Holmes et al., 2010), vascular smooth muscle cell (Esteban et al., 2011), and cancer cell (Espinosa et al., 2009), indicating that common mechanisms may exist for Rcan 1 to regulate cell migration.

The Rcanl gene consists of seven exons, of which exons 1 and 4 can be alternatively transcribed or spliced to produce different mRNA isoforms (Davies et al., 2007). All mRNA isoforms share exons 5-7, encoding 168 amino acids. The primary protein isoforms, initiated at exon 1 and exon 4 separately, are designated as Rcan 1-1 and Rcan1-4 (Harris et al., 2005; Davies et al., 2007). In agreement with previous findings in mice (Porta et al., 2007; Martin et al., 2012), we found that both Rcan1-1 and Rcan1-4 are also expressed in the rat cortex (Fig. 1A). Furthermore, a band with size between Rcan1-1 and Rcan1-4 was observed in Western blot (Fig. 1A). This band probably corresponds to another isoform of Rcan1 because its expression was downregulated by our shRNA (our unpublished observation). Previous studies have demonstrated that there are two translation initiation sites in the Rcan1-1 transcript, which may lead to translation of two protein isoforms (Rcan1-1L and Rcan1-1S) (Harris et al., 2005; Davies et al., 2007). Here, the observed extra band may correspond to the Rcan1-1S.

We show that only expression of Rcan $1-1$ could rescue the migration defect and the abnormal periventricular neuronal clustering of those Rcan1-knockdown neurons (Fig. 5), suggesting that Rcan 1-1 may play a major role in neuronal radial migration. An interesting question is what makes Rcan1-1 and Rcan 1-4 functionally different during neuronal migration. The rat Rcan1-1 and Rcan1-4 proteins share the same C-terminal region (171 amino acids) but have different $\mathrm{N}$-terminal region (80 amino acids for Rcan1-1 and 28 amino acids for Rcan1-4) (Harris et al., 2005), which may differentially interact with specific partners or be modulated by specific signaling pathways, leading to distinct cellular functions.

An interesting abnormality caused by Rcan 1 knockdown is the formation of PH (Fig. 4). Mutations in two genes, FLNA and $A D P$-ribosylation factor guanine exchange factor 2 (ARFGEF2), have been identified to associate with congenital $\mathrm{PH}$ in humans (Fox et al., 1998; Sheen et al., 2004). Interestingly, we found that Rcan 1 could regulate Flna expression at the mRNA level. Furthermore, the migration defect and the abnormal periventricular neuronal clustering caused by Rcan 1 knockdown can be rescued by FLNA overexpression, indicating that Flna acts downstream of Rcan 1 to regulate cortical neuronal migration. In addition, we found that knockdown Rcanl decreased the neural progenitor pool size, possibly because of impaired progenitor proliferation. Interestingly, a similar phenotype can be observed in Flna-null mice (Lian et al., 2012), suggesting that Flna may also mediate the function of Rcan 1 in progenitor development.

It is still unclear how the expression of Flna mRNA is regulated by Rcan1. The reduced Flna mRNA in Rcan1 knockdown neurons may be due to decreased mRNA transcription. Because alteration of calcineurin activity did not affect Flna mRNA expression, it seems unlikely that the canonical Rcan1-calcineurinNFAT signaling pathway (Rothermel et al., 2003; Harris et al., $2005)$ is involved. In addition to regulating its transcription, Rcan1 may also affect the stability of Flna mRNA (Fig. 8). Recently, Rcan 1 was found to interact with Fragile X mental retardation protein (FMRP) and regulate both dendritic spine morphogenesis and local protein synthesis (Wang et al., 2012), suggesting a functional link between Rcan1 and FMRP. As an RNA-binding protein that regulates the local mRNA translation (Bassell and Warren, 2008), FMRP also regulates mRNA stability (Zalfa et al., 2007; De Rubeis and Bagni, 2010). The findings that Flna expression is altered in FMRP-defective Drosophila (Bolduc, 2010) and FMRP knock-out mice (Liao et al., 2008) suggest that FMRP may regulate Flna expression. More interestingly, the observation of $\mathrm{PH}$ in patients with fragile-X syndrome (Parrini, 2006) further suggest a possible link between FMRP and FLNA. In future studies, it would be of interest to investigate whether the stability of Flna mRNA is regulated by the Rcan1-FMRP pathway.

\section{References}

Baek ST, Kerjan G, Bielas SL, Lee JE, Fenstermaker AG, Novarino G, Gleeson JG (2014) Off-target effect of doublecortin family shRNA on neuronal 
migration associated with endogenous microRNA dysregulation. Neuron 82:1255-1262. CrossRef Medline

Bassell GJ, Warren ST (2008) Fragile X syndrome: loss of local mRNA regulation alters synaptic development and function. Neuron 60:201-214. CrossRef Medline

Bolduc FV, Bell K, Rosenfelt C, Cox H, Tully T (2010) Fragile X mental retardation 1 and Filamin A interact genetically in Drosophila long-term memory. Front Neural Circuits 3:22. CrossRef Medline

Carabalona A, Beguin S, Pallesi-Pocachard E, Buhler E, Pellegrino C, Arnaud K, Hubert P, Oualha M, Siffroi JP, Khantane S, Coupry I, Goizet C, Gelot AB, Represa A, Cardoso C (2012) A glial origin for periventricular nodular heterotopia caused by impaired expression of Filamin-A. Hum Mol Genet 21:1004-1017. CrossRef Medline

Casas C, Martínez S, Pritchard MA, Fuentes JJ, Nadal M, Guimerà J, Arbonés M, Flórez J, Soriano E, Estivill X, Alcántara S (2001) Dscr1, a novel endogenous inhibitor of calcineurin signaling, is expressed in the primitive ventricle of the heart and during neurogenesis. Mech Dev 101:289292. CrossRef Medline

Chenn A, Walsh CA (2002) Regulation of cerebral cortical size by control of cell cycle exit in neural precursors. Science 297:365-369. CrossRef Medline

Davies KJ, Ermak G, Rothermel BA, Pritchard M, Heitman J, Ahnn J, Henrique-Silva F, Crawford D, Canaider S, Strippoli P, Carinci P, Min KT, Fox DS, Cunningham KW, Bassel-Duby R, Olson EN, Zhang Z, Williams RS, Gerber HP, Pérez-Riba M, et al. (2007) Renaming the DSCR1/ Adapt78 gene family as RCAN: regulators of calcineurin. FASEB J 21: 3023-3028. CrossRef Medline

De Rubeis S, Bagni C (2010) Fragile X mental retardation protein control of neuronal mRNA metabolism: insights into mRNA stability. Mol Cell Neurosci 43:43-50. CrossRef Medline

Espinosa AV, Shinohara M, Porchia LM, Chung YJ, McCarty S, Saji M, Ringel MD (2009) Regulator of calcineurin 1 modulates cancer cell migration in vitro. Clin Exp Metastasis 26:517-526. CrossRef Medline

Esteban V, Méndez-Barbero N, Jiménez-Borreguero LJ, Roqué M, Novensá L, García-Redondo AB, Salaices M, Vila L, Arbonés ML, Campanero MR, Redondo JM (2011) Regulator of calcineurin 1 mediates pathological vascular wall remodeling. J Exp Med 208:2125-2139. CrossRef Medline

Fox JW, Lamperti ED, Ekpioðlu YZ, Hong SE, Feng Y, Graham DA, Scheffer IE, Dobyns WB, Hirsch BA, Radtke RA, Berkovic SF, Huttenlocher PR, Walsh CA (1998) Mutations in filamin 1 prevent migration of cerebral cortical neurons in human periventricular heterotopia. Neuron 21:13151325. CrossRef Medline

Fuentes JJ, Pritchard MA, Planas AM, Bosch A, Ferrer I, Estivill X (1995) A new human gene from the Down-syndrome critical region encodes a proline-rich protein highly expressed in fetal brain and heart. Hum Mol Genet 4:1935-1944. CrossRef Medline

Fuentes JJ, Genescà L, Kingsbury TJ, Cunningham KW, Pérez-Riba M, Estivill X, de la Luna S (2000) DSCR1, overexpressed in Down syndrome, is an inhibitor of calcineurin-mediated signaling pathways. Hum Mol Genet 9:1681-1690. CrossRef Medline

García E, Stracher A, Jay D (2006) Calcineurin dephosphorylates the C-terminal region of filamin in an important regulatory site: a possible mechanism for filamin mobilization and cell signaling. Arch Biochem Biophys 446:140-150. CrossRef Medline

Görlach J, Fox DS, Cutler NS, Cox GM, Perfect JR, Heitman J (2000) Identification and characterization of a highly conserved calcineurin binding protein, CBP1/calcipressin, in Cryptococcus neoformans. EMBO J 19: 3618-3629. CrossRef Medline

Harris CD, Ermak G, Davies KJ (2005) Multiple roles of the DSCR1 (Adapt78 or RCAN1) gene and its protein product Calcipressin 1 (or RCAN1) in disease. Cell Mol Life Sci 62:2477-2486. CrossRef Medline

Hilioti Z, Gallagher DA, Low-Nam ST, Ramaswamy P, Gajer P, Kingsbury TJ, Birchwood CJ, Levchenko A, Cunningham KW (2004) GSK-3 kinases enhance calcineurin signaling by phosphorylation of RCNs. Genes Dev 18:35-47. CrossRef Medline

Hoeffer CA, Dey A, Sachan N, Wong H, Patterson RJ, Shelton JM, Richardson JA, Klann E, Rothermel BA (2007) The Down syndrome critical region protein RCAN1 regulates long-term potentiation and memory via inhibition of phosphatase signaling. J Neurosci 27:13161-13172. CrossRef Medline

Holmes K, Chapman E, See V, Cross MJ (2010) VEGF stimulates RCAN1.4 expression in endothelial cells via a pathway requiring $\mathrm{Ca}^{2+} /$ calcineurin and protein kinase C- $\delta$. PLoS One 5:e11435. CrossRef Medline

Iizuka M, Abe M, Shiiba K, Sasaki I, Sato Y (2004) Down syndrome candidate region 1, a downstream target of VEGF, participates in endothelial cell migration and angiogenesis. J Vasc Res 41:334-344. CrossRef Medline

Keating DJ, Dubach D, Zanin MP, Yu Y, Martin K, Zhao YF, Chen C, Porta S, Arbonés ML, Mittaz L, Pritchard MA (2008) DSCR1/RCAN1 regulates vesicle exocytosis and fusion pore kinetics: implications for Down syndrome and Alzheimer's disease. Hum Mol Genet 17:1020-1030. CrossRef Medline

Lian G, Lu J, Hu J, Zhang J, Cross SH, Ferland RJ, Sheen VL (2012) Filamin a regulates neural progenitor proliferation and cortical size through Wee1-dependent Cdk1 phosphorylation. J Neurosci 32:7672-7684. CrossRef Medline

Liao L, Park SK, Xu T, Vanderklish P, Yates JR 3rd (2008) Quantitative proteomic analysis of primary neurons reveals diverse changes in synaptic protein content in fmr1 knockout mice. Proc Natl Acad Sci U S A 105: 15281-15286. CrossRef Medline

Li S, Zhang C, Takemori H, Zhou Y, Xiong ZQ (2009) TORC1 regulates activity-dependent CREB-target gene transcription and dendritic growth of developing cortical neurons. J Neurosci 29:2334-2343. CrossRef Medline

Liu J, Farmer JD Jr, Lane WS, Friedman J, Weissman I, Schreiber SL (1991) Calcineurin is a common target of cyclophilin-cyclosporine A and FKBPFK506 complexes. Cell 66:807-815. CrossRef Medline

Lu J, Sheen V (2005) Periventricular heterotopia. Epilepsy Behav 7:143149. CrossRef Medline

Mao Y, Ge X, Frank CL, Madison JM, Koehler AN, Doud MK, Tassa C, Berry EM, Soda T, Singh KK, Biechele T, Petryshen TL, Moon RT, Haggarty SJ, Tsai LH (2009) Disrupted in schizophrenia 1 regulates neuronal progenitor proliferation via modulation of GSK3 beta/beta-catenin signaling. Cell 136:1017-1031. CrossRef Medline

Martin KR, Corlett A, Dubach D, Mustafa T, Coleman HA, Parkington HC, Merson TD, Bourne JA, Porta S, Arbonés ML, Finkelstein DI, Pritchard MA (2012) Over-expression of RCAN1 causes Down syndrome-like hippocampal deficits that alter learning and memory. Hum Mol Genet 21:3025-3041. CrossRef Medline

Olson EC, Walsh CA (2002) Smooth, rough and upside-down neocortical development. Curr Opin Genet Dev 12:320-327. CrossRef Medline

Parrini E, Ramazzotti A, Dobyns WB, Mei D, Moro F, Veggiotti P, Marini C, Brilstra EH, Dalla Bernardina B, Goodwin L, Bodell A, Jones MC, Nangeroni M, Palmeri S, Said E, Sander JW, Striano P, Takahashi Y, Van Maldergem L, Leonardi G, et al. (2006) Periventricular heterotopia: phenotypic heterogeneity and correlation with Filamin A mutations. Brain 129:1892-1906. CrossRef Medline

Porta S, Martí E, de la Luna S, Arbonés ML (2007) Differential expression of members of the RCAN family of calcineurin regulators suggests selective functions for these proteins in the brain. Eur J Neurosci 26:1213-1226. CrossRef Medline

Rothermel BA, Vega RB, Williams RS (2003) The role of modulatory calcineurin-interacting proteins in calcineurin signaling. Trends Cardiovasc Med 13:15-21. CrossRef Medline

Rothermel B, Vega RB, Yang J, Wu H, Bassel-Duby R, Williams RS (2000) A protein encoded within the Down syndrome critical region is enriched in striated muscles and inhibits calcineurin signaling. J Biol Chem 275: 8719-8725. CrossRef Medline

Saito $T$ (2006) In vivo electroporation in the embryonic mouse central nervous system. Nat Protocols 1:1552-1558. CrossRef Medline

Sarkisian MR, Bartley CM, Chi H, Nakamura F, Hashimoto-Torii K, Torii M, Flavell RA, Rakic P (2006) MEKK4 signaling regulates filamin expression and neuronal migration. Neuron 52:789-801. CrossRef Medline

Sarkisian MR, Bartley CM, Rakic P (2008) Trouble making the first move: interpreting arrested neuronal migration in the cerebral cortex. Trends Neurosci 31:54-61. CrossRef Medline

Sheen VL, Dixon PH, Fox JW, Hong SE, Kinton L, Sisodiya SM, Duncan JS, Dubeau F, Scheffer IE, Schachter SC, Wilner A, Henchy R, Crino P, Kamuro K, DiMario F, Berg M, Kuzniecky R, Cole AJ, Bromfield E, Biber M, et al. (2001) Mutations in the X-linked filamin 1 gene cause periventricular nodular heterotopia in males as well as in females. Hum Mol Genet 10:1775-1783. CrossRef Medline

Sheen VL, Ganesh VS, Topcu M, Sebire G, Bodell A, Hill RS, Grant PE, 
Shugart YY, Imitola J, Khoury SJ, Guerrini R, Walsh CA (2004) Mutations in ARFGEF2 implicate vesicle trafficking in neural progenitor proliferation and migration in the human cerebral cortex. Nat Genet 36:69-76. Medline

Tabata H, Nakajima K (2001) Efficient in utero gene transfer system to the developing mouse brain using electroporation: visualization of neuronal migration in the developing cortex. Neuroscience 103:865-872. CrossRef Medline

Tocci MJ, Matkovich DA, Collier KA, Kwok P, Dumont F, Lin S, Degudicibus S, Siekierka JJ, Chin J, Hutchinson NI (1989) The immunosuppressant Fk506 selectively inhibits expression of early T-cell activation genes. J Immunol 143:718-726. Medline

Vega RB, Yang J, Rothermel BA, Bassel-Duby R, Williams RS (2002) Multiple domains of MCIP1 contribute to inhibition of calcineurin activity. J Biol Chem 277:30401-30407. CrossRef Medline
Vega RB, Rothermel BA, Weinheimer CJ, Kovacs A, Naseem RH, BasselDuby R, Williams RS, Olson EN (2003) Dual roles of modulatory calcineurin-interacting protein 1 in cardiac hypertrophy. Proc Natl Acad Sci U S A 100:669-674. CrossRef Medline

Wang W, Zhu JZ, Chang KT, Min KT (2012) DSCR1 interacts with FMRP and is required for spine morphogenesis and local protein synthesis. EMBO J 31:3655-3666. CrossRef Medline

Zalfa F, Eleuteri B, Dickson KS, Mercaldo V, De Rubeis S, di Penta A, Tabolacci E, Chiurazzi P, Neri G, Grant SG, Bagni C (2007) A new function for the fragile $\mathrm{X}$ mental retardation protein in regulation of PSD-95 mRNA stability. Nat Neurosci 10:578-587. CrossRef Medline

Zhou Y, Wu H, Li S, Chen Q, Cheng XW, Zheng J, Takemori H, Xiong ZQ (2006) Requirement of TORC1 for late-phase long-term potentiation in the hippocampus. PLoS One 1:e16. CrossRef Medline 